\title{
Chasing the queens of the alien predator of honeybees: A water drop in the invasiveness ocean
}

\author{
Karine Monceau ${ }^{1,2}$, Olivier Bonnard ${ }^{1,2}$, Denis Thiéry ${ }^{1,2^{*}}$ \\ ${ }^{1}$ Institut National de la Recherche Agronomique, UMR1065 Santé et Agroécologie du Vignoble, Institut des Sciences de la Vigne et \\ du Vin (ISVV), Villenave d’Ornon, France; ${ }^{*}$ Corresponding Author: thiery@bordeaux.inra.fr \\ ${ }^{2}$ Université de Bordeaux, UMR1065 Santé et Agroécologie du Vignoble, Bordeaux Sciences Agro, Villenave d’Ornon, France
}

Received 31 July 2012; revised 5 September 2012; accepted 13 September 2012

\begin{abstract}
The Yellow-legged hornet, Vespa velutina, was accidentally introduced in France in 2004, and then spread rapidly through the French territory but also to adjacent European countries (Spain, Portugal, and Belgium). During summer and autumn, V. velutina workers hunt domestic honeybees, Apis mellifera, for feeding their larvae. The impact of this alien species is mainly economic, beekeepers experiencing heavy colony losses, but also ecological, $v$. velutina hunting other pollinators. In their year-round life cycle, nest initiation by single queen during spring is the critical stage. In invaded areas, spring queen trapping using food baits has been promoted by apicultural unions in order to limit $V$. velutina population expansion. The goals of this work were 1) to evaluate the yield of this method, 2) to identify appropriate sites for trapping, 3) to identify potential optimal climatic windows of capture, and 4) to quantify the impact on local entomofauna. Our results showed that water proximity enhances trapping but not beehives proximity, and that trapping is inefficient if average week temperatures are below $10^{\circ} \mathrm{C}$. Although the trapping effect on biodiversity should be studied more carefully, spring queen trapping is highly questionable unless specific attractants could be proposed.
\end{abstract}

Keywords: Foundress; Invasive Species; Metareplication; Vespa velutina; Yellow-Legged Hornet

\section{INTRODUCTION}

The recent biological invasion of the Yellow-legged hornet, Vespa velutina, in France raises an important ecological problem because this Vespidae predates domestic honeybees, Apis mellifera. Its introduction is at- tributed to boat shipment from China of a single queen [1]. The first installed colony was observed close to Agen in south-western France in 2005 [2,3]. Since this introduction, local predation on honeybees started and was rapidly noticed by beekeepers. This is the first biological invasion by a Vespidae species the European area has had to deal with [4-6]. To date, almost half of the French regions is colonised, and $V$. velutina is currently expanding to neighbouring countries: Spain [7], Portugal (A. Goldarazena, pers.com) and Belgium [8]. Italy could probably be invaded in a near future since several nests were detected in 2011 in the region of Nice near the Italian boundary. Moreover, a simulation predicted a geographical expansion along the Mediterranean coast [9].

The consequences of $V$. velutina invasion are at least three. The first one is obviously ecological because the Yellow-legged hornet predates numerous honeybees but also other pollinators, thus potentially affecting insect pollinated plants. The second effect is economic, beekeeper activities being directly affected by their colony losses. The third obvious impact concerns the human population. Indeed, $V$. velutina colonies are mostly located close to rivers, lakes and cities, and because of the spectacular large-sized nests at autumn, it starts generating a frenzy even if French Control Poison Centres reported in 2007 no significant increase of Hymenoptera stings [10] and only two cases of death by $V$. velutina envenomation has been confirmed to date.

Like other Vespinae, $V$. velutina nests are initiated by a single queen $[1,11]$. Each year, a single queen can produce up to several hundreds of individuals from spring to autumn, generating intense predation pressure on honeybees. During nest initiation, foundresses basically need water to build their primary nest, carbohydrates for energy and proteins to feed their larvae. Although total eradication is probably no more possible and geographical area extension is in progress, several methods have been proposed to limit $V$. velutina impact such as trapping hunters in apiaries or foundresses during spring. 
The most critical stage of the year-round life cycle occurs during nest initiation by single foundress [11]. Beekeepers unions currently promote the general use of food traps against $V$. velutina foundresses during the nest initiation in early spring [12]. Sweet baits dissolved in water can be used to lure foundresses because they provide carbohydrates. However, this method is subjected to controversy $[12,13]$. To date, only one $V$. velutina spring queen trapping study has been published [13]. Nonetheless, many ecologists recommend to realise metareplications (the replication of an entire study but with different methodology, experimenters, locations, or years [14]), particularly in wildlife researches [15]. Such a methodology is particularly helpful to avoid wrong conclusions arising from specific situations, and thus metareplication provides either a support for the consistency of the results or alternative interpretations [14-19].

The lack of metareplication of $V$. velutina spring queen trapping study and the growing extension of such trapping in France, conducted us to replicate in 2011 and in another area, the previous study realised in 2009 [13]. Here, we tested the efficiency of spring queen trapping and its relation with temperature, an important factor in Vespidae foraging activities [20-22] but also in the number of flying queens [23]. We also tested the effect of the vicinity of water source and beehives which can provide the basic ingredient for nest construction [11] and a food source for feeding larvae.

\section{MATERIAL AND METHODS}

\subsection{Study Area and Attractive Baits}

Spring queen trapping was realised in two areas (cities): Mérignac (MER, GPS: 4450'41.56"N, 0³9'22.89"
W) and Villenave d'Ornon (VIL, GPS: $44^{\circ} 47^{\prime} 27.05^{\prime \prime} \mathrm{N}$, $0^{\circ} 34 ' 38.35 \mathrm{~W}$ ), distant approximately of $10 \mathrm{~km}$. In each area, traps were placed respectively in three and two sites. In MER, experiment was conducted in the city centre (urban area), in the park of the city Hall and in a private property (Table 1). In VIL, trapping was realised around the experimental apiary of La Grande Ferrade (Institut National de la Recherche Agronomique, thereafter noted INRA, Villenave d'Ornon) and in the adjacent public park of Soureil (Table 1).

Water proximity (natural ponds) and/or beehives was based on a distance of twenty meters: traps placed in less than twenty meters from a water source and/or hives (range: $1 \mathrm{~m}-20 \mathrm{~m}$ ) were opposed to those placed in more than twenty meters from a water source and/or hives (range: $100 \mathrm{~m}$ - $600 \mathrm{~m}$, Table 1).

Two types of traps were used. The first one is a classical funnel trap design (Figure 1(a)) and the second one is based on the same principle but it is implemented of holes allowing small insects but not $V$. velutina to escape from the traps, and of a sponge soak with bait to reduce insect mortality due to drowning (Figure 1(b)). In VIL, two baits based on a mix with beer (to avoid honeybee trapping) were used: one with honey (HB) and the second with blackcurrant syrup (CB see Table 1 for details). The CB bait was used with classical funnel trap, while the HB bait was used with derived funnel trap (Figure 1(b)). In MER, only CB was used classical funnel traps.

Traps were weekly monitored for all sites, on Monday in VIL and on Wednesday in MER. In VIL, queen trapping began on the $21^{\text {st }}$ of February 2011 (first checking on the $28^{\text {th }}$ of February week). In MER, queen trapping began on the $21^{\text {st }}$ of March 2011 (first checking on the

Table 1. Number of traps (N), baits (CB: blackcurrant-beer, HB: honey-beer), vicinity to water and to beehives (yes or no) for all study sites in MER and VIL.

\begin{tabular}{|c|c|c|c|c|}
\hline Area/Site & $\mathrm{N}$ & Bait & Water & Beehives \\
\hline \multicolumn{5}{|l|}{ VIL } \\
\hline \multirow[t]{4}{*}{ Soureil } & 1 & $\mathrm{HB}$ & Yes & Yes \\
\hline & 1 & $\mathrm{HB}$ & No & No \\
\hline & 1 & $\mathrm{CB}$ & Yes & Yes \\
\hline & 1 & $\mathrm{CB}$ & No & No \\
\hline \multirow[t]{4}{*}{ INRA } & 1 & HB & No & Yes \\
\hline & 1 & $\mathrm{HB}$ & No & Yes \\
\hline & 1 & СВ & No & Yes \\
\hline & 1 & $\mathrm{CB}$ & No & Yes \\
\hline \multicolumn{5}{|l|}{ MER } \\
\hline City centre & 3 & $\mathrm{CB}$ & No & No \\
\hline City Hall park & 4 & $\mathrm{CB}$ & Yes & No \\
\hline Private property & 1 & $\mathrm{CB}$ & No & No \\
\hline
\end{tabular}




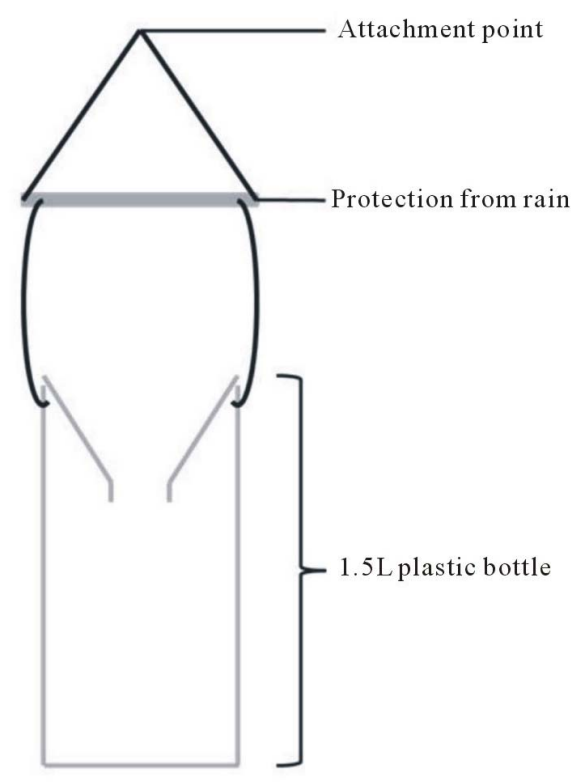

(a)

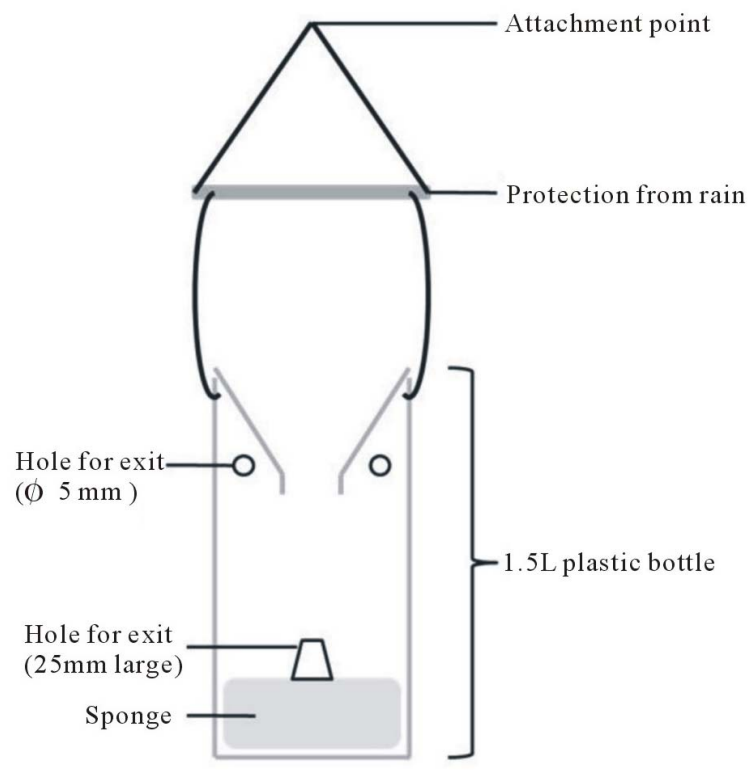

(b)

Figure 1. Funnel trap designs used in this study: a) Classical funnel trap design and b) funnel trap design implemented of exit holes (according to Mr. Jean-Paul Cros from the Association Action Anti Frelon Asiatique de Gironde, AAAFA33, http://anti-frelon-d-asie-jp33.over-blog.com).

$28^{\text {th }}$ of March week). Both surveys ended on the week of the $9^{\text {th }}$ of May (last checking on the $11^{\text {th }}$ of May) when the first workers were trapped. To allow comparisons between sites, only the matching periods were used for the analyses from the $21^{\text {st }}$ of March 2011 (week 1) to the $9^{\text {th }}$ of May (week 7). The period from the $21^{\text {st }}$ of February to the $21^{\text {st }}$ of March 2011 in VIL was only used for temperature effect on trapping and represented only a single $V$. velutina queen.

\subsection{Data Acquisition}

Trap contents were collected, insects scored, and assigned to taxonomic groups (order for most of them). Hornets were then dried [24] at $70^{\circ} \mathrm{C}$ in a stove for at least two hours and then, weighted to the nearest $0.1 \mathrm{mg}$ using a precision scale (Sartorius MC 210 S). Thirteen individuals were not weighted due to their poor conditions.

Temperatures for the VIL experimental site were obtained by INRA weather station located in La Grande Ferrade (extraction from the database done by the Climatik application v. 1.2, Agroclim INRA), and averaged in order to get a mean temperature between two consecutive dates.

\subsection{Data Analysis}

The difference in bait attractiveness was assessed with non-parametric Mann-Whitney $U$ tests (rank test for independent observations). The body mass variation between dates and cities was tested using an analysis of variance, i.e. ANOVA (after checking for normality and homoscedasticity with respectively Shapiro-Wilk and Levene tests). Statistical significance of each term was assessed with $F$-statistics. Catching differences per weeks between and within areas, the temperature effect and the effect of the vicinity of water and beehives were tested with Poisson log-linear Generalised Linear Models (GLMs). For temperature effect, temperature was included in the model both as linear and quadratic variable to account for potential optimum effect. Deviance of the Poisson log-linear GLM was tested against degrees of freedom using $\chi^{2}$ distribution in order to detect and then account for potential overdispersion which is classical for count data [25]. Statistical significance of each parameter was then assessed with likelihood ratio-based $\chi^{2}$ statistics. A post hoc multiple comparison tests was used after the GLM test for catching differences per weeks to identify differences between groups.

All statistics were done using R software v. 2.15.0 [26] implemented with epicalc package ("poisgof" function for overdispersion detection) and dispmod package ("glm.poisson.disp" function for Poisson log-linear GLM overdispersion correction).

\section{RESULTS}

Captures of $V$. velutina in both cities from the $21^{\text {st }}$ of March to the $9^{\text {th }}$ of May scored 80 queens (55 in MER and 25 in VIL) with 16 traps during seven weeks which 
overall yielded 0.71 female per trap per week (0.98 in MER and 0.45 in VIL). In VIL, if we accounted for the first period (from the $21^{\text {st }}$ of February to the $21^{\text {st }}$ of March 2011, scoring only one queen) the yield fell to 0.29 .

\subsection{Attractiveness and Selectivity of Traps for Vespa velutina Queens and other Species (VIL Only)}

There was no difference in attractiveness between CB and HB for $V$. velutina (Mann-Whitney $U$ test, Soureil: Z $=130.5, \mathrm{P}=0.10, \mathrm{~N}=28$; INRA: $\mathrm{Z}=112.5, \mathrm{P}=0.29, \mathrm{~N}$ = 28; overall: $\mathrm{Z}=483.5, \mathrm{P}=0.06, \mathrm{~N}=56$ ).

Thus, sample from both baits were pooled for subsequent analyses on $V$. velutina numbers. Overall, CB and $\mathrm{HB}$ trapped equivalent quantity of other species, except for Dipterans which is most probably due to the possibility of escape through exit holes (Table 2). Considering the total sample, $V$. velutina represented only $1.70 \%$ of the individuals trapped (all traps mixed).

\subsection{Trapping Dynamics and Differences Between Cities and Sites}

Overall, more foundresses were trapped in MER than in VIL (GLM, Poisson family corrected for overdispersion: $\chi_{1}^{2}=6.09, \mathrm{P}=0.01$ ) with differences within cities between sites $\left(\chi_{3}^{2}=10.15, \mathrm{P}=0.02\right.$, Figure 2$)$, due to differences between MER-city Hall and VIL-INRA (Post hoc multiple comparison test, $\mathrm{P}=0.03$, all other P-values $>0.15)$. Trapping efficiency differed between weeks $\left(\chi_{1}^{2}=4.68, \mathrm{P}=0.03\right.$, Figure 3 ) with the same trend in both cities $\left(\chi_{1}^{2}=0.11, \mathrm{P}=0.74\right)$ and sites $\left(\chi_{3}^{2}=2.94, \mathrm{P}=\right.$ 0.40 ). All sites combined, most of foundresses were trapped between the $22^{\text {nd }}$ of March and the $27^{\text {th }}$ of April with a pick the first week of April (from the $4^{\text {th }}$ to the $13^{\text {th }}$ of April).

\subsection{Vicinity of Water and Beehives}

A weak effect of the vicinity of water appeared (GLM, Poisson family corrected for overdispersion: $\chi_{1}^{2}=4.06, \mathrm{P}$ $=0.04)$ : more foundresses were caught in traps located closed to water sources $\left(\mathrm{N}_{\text {water }}=41\right)$. At the opposite, beehive proximity did not favour trapping since less foundresses were caught in traps located closed to hives $\left(\chi_{1}^{2}=\right.$ $5.48, \mathrm{P}=0.02, \mathrm{~N}_{\text {beehives }}=17$ ).

\subsection{Temperature Effect on Trapping (VIL Only)}

Best model for fitting relation between queen trapping and mean temperature included a quadratic effect of temperature (GLM Poisson family: linear temperature effect: $\chi_{1}^{2}=5.33, P=0.02$, and quadratic temperature effect: $\chi_{1}^{2}=17.22, \mathrm{P}<0.0001$, Figure 4). No capture was observed below temperature $10^{\circ} \mathrm{C}$ and the best scores were reached at $15^{\circ} \mathrm{C}$.

Table 2. Comparison of non-target species yields between CB and HB traps in VIL. Mann-Whitney $U$ test values (Z) and associated probabilities $(\mathrm{P})$, number of individuals caught in $\mathrm{CB}(\mathrm{Ncb})$ and in HB (Nhb) are specified. Significant probabilities after Bonferroni's correction $(\mathrm{P}=0.007)$ are in bold.

\begin{tabular}{|c|c|c|c|c|c|c|}
\hline & & INRA & & & Soureil & \\
\hline & Z & $\mathrm{P}$ & Ncb/Nhb & Z & $\mathrm{P}$ & Ncb/Nhb \\
\hline Vespa crabro & 105.0 & 0.35 & $1 / 0$ & 137.0 & 0.03 & $14 / 2$ \\
\hline Wasps & 105.0 & 0.35 & $1 / 0$ & 105.0 & 0.35 & $1 / 0$ \\
\hline Honeybees & 84.5 & 0.33 & $3 / 13$ & - & - & $0 / 0$ \\
\hline Diptera & 174.5 & $<0.001$ & $587 / 65$ & 196.0 & $<0.0001$ & $438 / 11$ \\
\hline Lepidoptera & 100.0 & 0.94 & $35 / 23$ & 116.5 & 0.35 & $72 / 12$ \\
\hline Arachnids & 98.0 & 1.00 & $1 / 1$ & 105.0 & 0.35 & $1 / 0$ \\
\hline Others & 118.5 & 0.27 & $83 / 51$ & 110.0 & 0.49 & $50 / 9$ \\
\hline
\end{tabular}




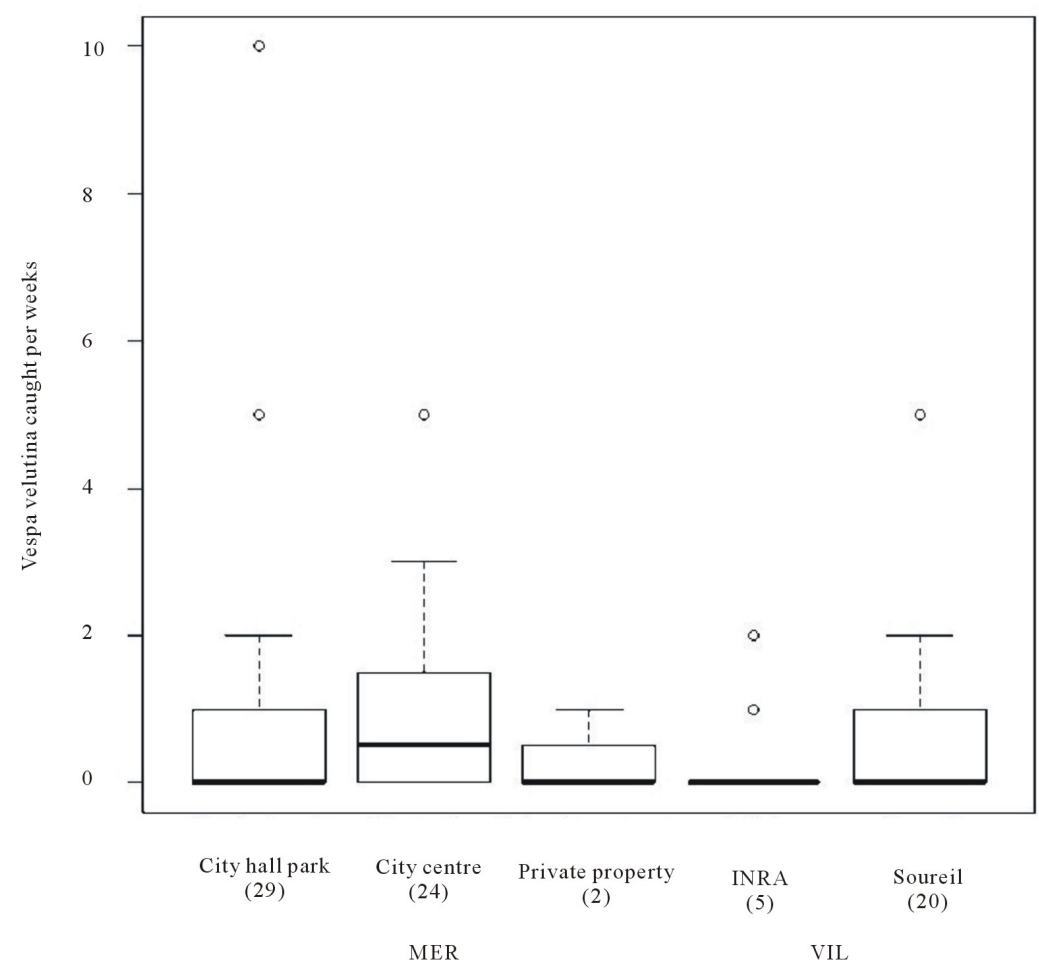

Figure 2. Number of Vespa velutina queens trapped per week in each site with the total number of trapped hornets in brackets. Boxes, plain line, dash lines and open circles represent $50 \%$ of all values, medians, $1.5 \times$ interquartile range and extreme values respectively.

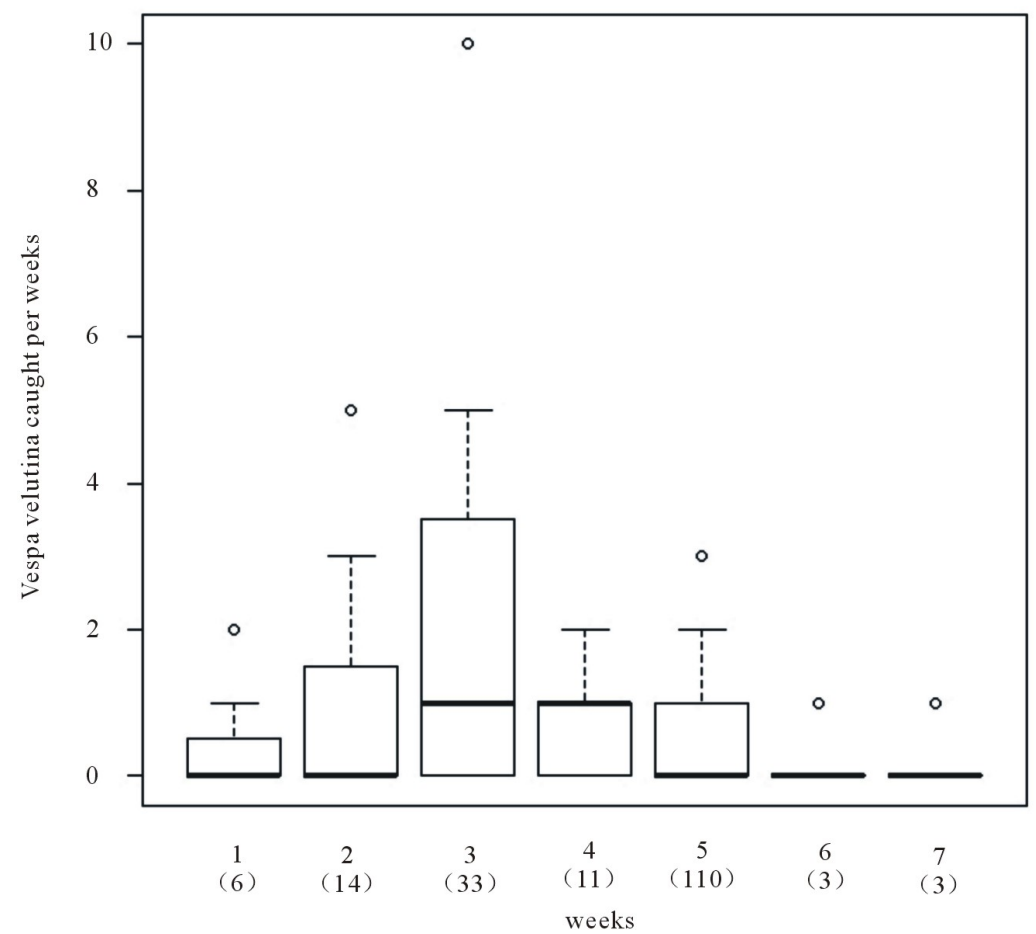

Figure 3. Weekly variation of trapped queens (all sites pooled), from week $1\left(21^{\text {st }}\right.$ of March) to week 7 ( $9^{\text {th }}$ of May) with the total number of trapped hornets in brackets. Boxes, plain line, dash lines and open circles represent $50 \%$ of all values, medians, $1.5 \times$ interquartile range and extreme values respectively. 


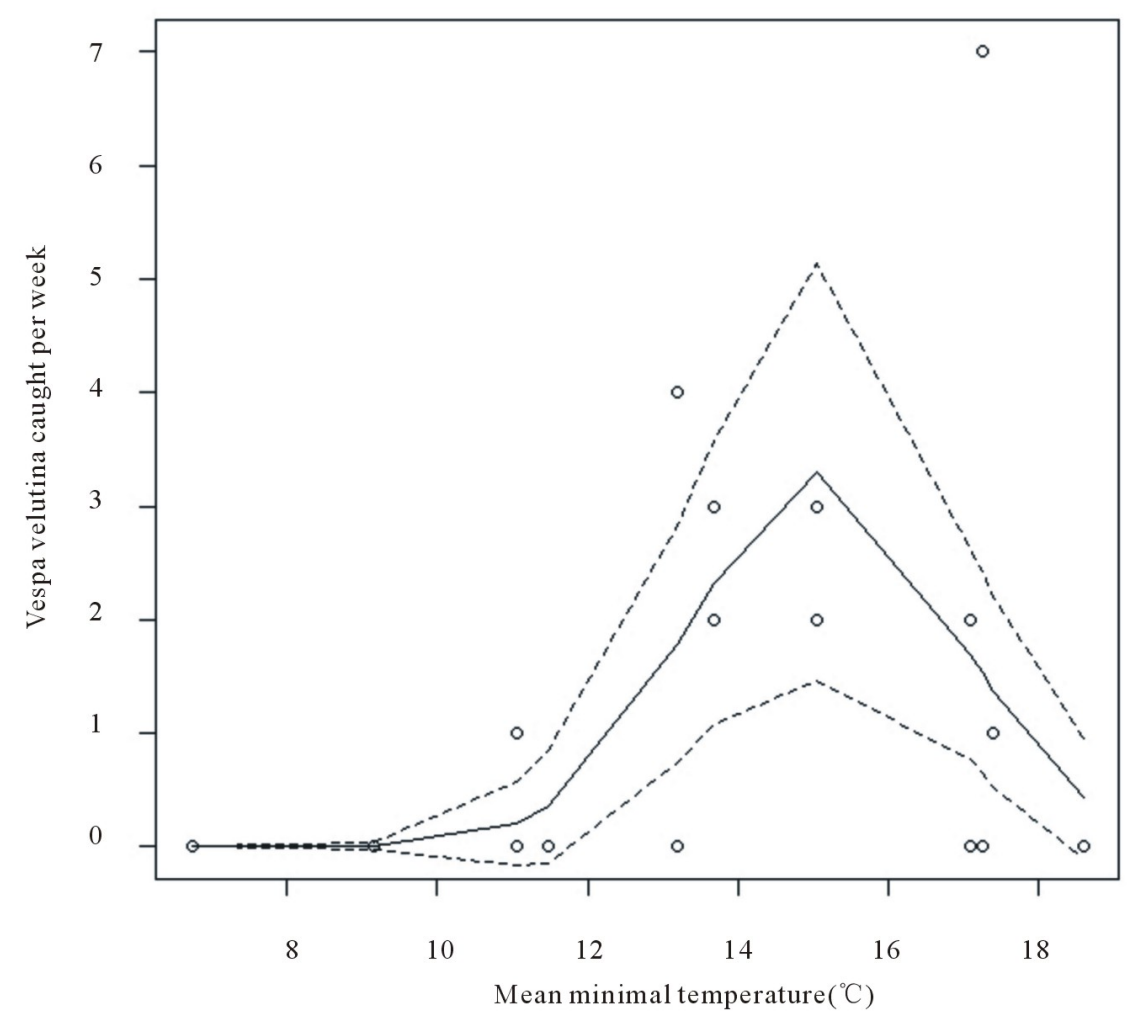

Figure 4. Number of Vespa velutina queens trapped according to mean temperature, based on predicted values fitted with GLM model (plain line) assorted with 95\% confidence interval (dash lines).

\subsection{Body Mass Variation}

Foundresses' body mass was similar between MER and VIL (ANOVA: $\mathrm{F}_{1.55}=2.43, \mathrm{P}=0.12$ ) and between weeks $\left(\mathrm{F}_{6.55}=0.84, \mathrm{P}=0.54\right)$ with no interaction $\left(\mathrm{F}_{4.55}=\right.$ $0.75, P=0.56)$. Nevertheless, for the last week, body mass variability was clearly higher due to a smaller individual which was probably a worker if considering its lower body mass (78.06 mg, Figure 5).

\section{DISCUSSION}

\subsection{Queen Trapping Efficiency}

In our study, 80 foundresses (excluding the single one caught earlier in VIL) were trapped. In early 2011, at least 10 nests (colonies founded in 2010) were detected in the vicinity of INRA and Soureil in VIL.

According to the survival rates based on the number of nests detected each year since 2004, these 10 nests should have produced more than one hundred of queens (111), each one producing a new colony the next year. Thus, the 26 queens we have trapped were few in a location where one should have expected more than one hundred queens. Thus, we consider that such trapping is far from being efficient. However, our estimation does not take into account long-range dispersion because we do not know how $V$. velutina queens disperse. An efficient management plan should consider this kind of parameters but to date, this information is missing.

The overall yield of our trapping experiment was 0.71 female per trap per week. Even though it appears low, this efficiency was much higher than the previous study [13] that is 0.01 female per trap per week (eight foundresses with 90 traps during eight weeks). Although the period of trapping can have strong effect on the yields (see the example of VIL), their study was realised from the $23^{\text {rd }}$ of March until the $18^{\text {th }}$ of May 2009, thus corresponding to the same duration. Such a difference can probably be explained by different population levels between these two studies. Differences in weather conditions could also explain such differences. Indeed, temperature effect on Vespidae activity is well known [20-22]. In $V$. velutina, temperature modulates the overall activity at nest [27]. Here, we show that trapping started above an average week temperature of $10^{\circ} \mathrm{C}$ and reached an optimum at $15^{\circ} \mathrm{C}$. Thus, queen trapping is not necessary when temperature is below this limit, and removing or closing the traps below this temperature could be a way for adverse effects on biodiversity. Our results also point the importance of trap location. Water source and diverse types of wood fibre proximity as basic elements for nest building are essential [11,24]. Nests are often found in 


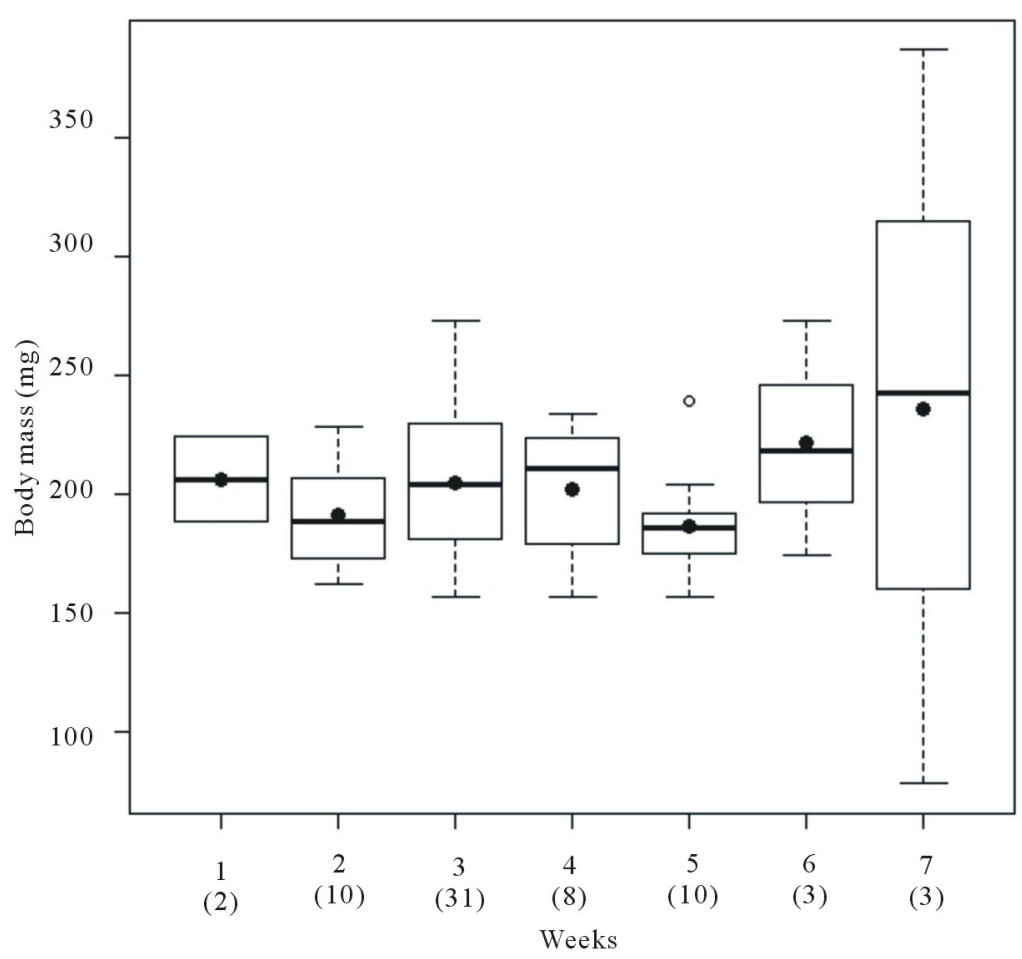

Figure 5. Body mass variations of Vespa velutina queens trapped during the survey, from week 1 ( $21^{\text {st }}$ of March) to week 7 ( $9^{\text {th }}$ of May) with the total number of trapped hornets in brackets. Boxes, plain line, black point, dash lines and open circle represent $50 \%$ of all values, medians, means, $1.5 \times$ interquartile range and extreme value respectively.

poplar treetops which are present in riparian forest. Thus, using this trapping technique in the vicinity of important water source should be promoted in future monitoring or spring management strategies. Inversely, hive proximity provided low capture rates which suggests that protein requirement for feeding larvae occurs later or that queens chase on other insects. We thus discourage from placing traps close to hives.

\subsection{Body Mass, Trapping Dynamics and Bet-Hedging Strategy}

Nest initiation in Vespidae does not begin soon after the emergence of queens but takes a delay from few days to a couple of weeks [28]. Spring queen trapping exploits the fact that during this pre-nesting period, foundresses search for carbohydrate sources such as flower nectar or tree sap [29]. Basically, most of the fat contents of queens are used during overwintering [11]. Nevertheless, these heavy losses are not compensated after the emergence by carbohydrate intakes because these later are only collected to provide energy for pre-nesting activities. Consequently, the queen body mass does not increase during spring [11].

Our trapping data illustrate that $V$. velutina queens begin to feed on carbohydrates in the end of March until early May with a peak occurring early April. Such a long period of flight activity is coherent with those reported in several Vespidae species (e.g. V. crabro or Vespula rufa, $[11,24])$. This result suggests that overwintering emergences of $V$. velutina foundresses are spread over time. Overwintering duration variability has been described in insects as a bet-hedging strategy to adapt to novel environments [30]. Such a trait could provide a fitness benefit in $V$. velutina by enhancing nest foundation success. It could thus represent a valuable strategy to increase the performances of invasion.

\subsection{Impact on Local Entomofauna}

Other insect species were attracted to sweet baits. Especially, Dipterans are often expected to pay a heavy tribute in such spring trapping campaigns. To some extent, we confirm conclusions made by summer trappings [31] and spring ones [13]. Anyway, the use of funnel traps with lateral holes and sponge should be preferred to classical ones, as they limit the impact on non-target species. One major criticism that could be formulated against these studies (including ours) is to only provide a qualitative aspect of the non-selectivity of trapping. Data on the effect of the method on non-target species population dynamics which is probably a better estimator 
should be provided to assess the real negative impact of this method. Indeed, we are in a critical position balancing between deleterious effects on entomofauna, which is yet not clearly measured, and the use of a tool to control a predator of pollinators. Obviously, finding specific attractants like pheromones in future would be the best option. Thus, the best current solution is to find a realistic compromise between efficiency and deleterious effects, like for any trapping strategies in agriculture.

\subsection{Concluding Remarks for Vespa velutina Management}

Four lessons can be drawn from our experiment for $V$. velutina management: 1) traps placed close to water source are slightly more efficient than the others, 2) spring apiary protection is not necessary, 3) trapping yields no capture when mean daily temperatures is below $10^{\circ} \mathrm{C}$ and thus, trap installation should be adapted to local average temperatures, and 4) queen trapping cannot clearly be considered useful because it does not seem to significantly reduce the population level.

Although we agree with the conclusion of the previous study on the potential impact on local entomofauna [13], we encourage further well-designed experiments integrating the ecological functionality of each targeted species to quantify the exact deleterious effect of spring trapping. Overall, the results obtained in the present study confronted to the results previously obtained [13] illustrate the risk to generalise conclusions from a single study and thus highlight the usefulness of metareplication.

One may conclude from the present study that $V$. velutina queen trapping is a drop in the invasiveness ocean, and this method may appear as a "bandage on a wooden leg” for honeybee protection. Nevertheless, could one discourage from queen trapping when facing a trade-off between attempting any methods that could protect honeybees and the risk against insect biodiversity, which is not yet confirmed? The devil's advocate would argue that if queens were not trapped, insect biodiversity would also suffer later from $V$. velutina predation. Thus, instead of prohibiting queen trapping, this method should be improved, for example using more specific attractants e.g. pheromones. In the absence of such products, the use of classical funnel trap design implemented of holes (to allow part of non-target species to escape) should be considered. Obviously, such practices must also be regularly monitored to limit collateral damages to entomofauna and highlight the need to set up a management network.

\section{ACKNOWLEDGEMENTS}

This research project was funded by a France Agrimer grant \# 797/2007 2010. Article contribution: KM and DT: redaction; KM, OB, and DT: ex- perimental conception; $\mathrm{KM}$ and $\mathrm{OB}$ : data acquisition; KM and DT: data processing. We are particularly grateful to Mérignac municipality and particularly to Mr. Lafargue from Prévention, Santé, Sécurité services, and to Mr. Jean-Paul Cros from the Association Action Anti Frelon Asiatique de Gironde (AAAFA33, http://anti-frelon-d-asie-jp33.over-blog.com) for providing us derived funnel traps.

\section{REFERENCES}

[1] Arca, M. (2012) Caractérisation génétique et étude comportementale d'une espèce envahissante en France: Vespa velutina Lepeletier (Hymenoptera, Vespidae). Ph.D. Thesis, Université Pierre et Marie Curie, Paris.

[2] Haxaire, J., Bouguet, J.-P. and Tamisier, J.-P. (2006) Vespa velutina Lepeletier, 1836, une redoutable nouveauté pour la faune de France (Hymenoptera: Vespidae). Bulletin de la Société Entomologique de France, 111, 194.

[3] Villemant, C., Haxaire, J. and Streito, J.-C. (2006) Premier bilan de l'invasion de Vespa velutina Lepeletier en France (Hymenoptera, Vespidae). Bulletin de la Société Entomologique de France, 111, 535-538.

[4] Rortais, A., Villemant, C., Gargominy, O., Rome, Q., Haxaire, J., Papachristoforou, A. and Arnold, G. (2010) A new enemy of honeybees in Europe: The Asian hornet Vespa velutina. In: Settele, J., Ed., Atlas of Biodiversity RisksFrom Europe to the Globe, From Stories to Maps. Pensoft, Sofia, 11.

[5] Beggs, J.R., Brockerhoff, E.G., Corley, J.C., Kenis, K., Masciocchi, M., Muller, F., Rome, Q. and Villemant, C. (2011) Ecological effects and management of invasive Vespidae. Biological Control, 56, 505-526. doi:10.1007/s10526-011-9389-z

[6] Roy, H.E., Roy, D.B. and Roques, A. (2011) Inventory of terrestrial alien arthropod predators and parasites established in Europe. Biological Control, 56, 477-504. doi:10.1007/s10526-011-9355-9

[7] López, S., Gonzáles, M. and Goldarazena, A. (2011) Vespa velutina Lepeletier, 1836 (Hymenoptera: Vespidae): First records in Iberian Peninsula. Bulletin OEPP/EPPO Bulletin, 41, 439-441.

[8] Bruneau, E. (2011) Le frelon asiatique, déjà là. ActuApi, 55, 1-6.

[9] Villemant, C., Barbet-Massin, M., Perrard, A., Muller, F., Gargominy, O., Jiguet, F. and Rome, Q. (2011) Predicting the invasion risk by the alien bee-hawking Yellow-legged hornet Vespa velutina nigrithorax across Europe and other continents with niche models. Biological Conservation, 144, 2142-2150. doi:10.1016/j.biocon.2011.04.009

[10] de Haro, L., Labadie, M., Chanseau, P., Cabot, C., BlancBrisset, I. and Penouil, F. (2010) Medical consequences of the Asian black hornet (Vespa velutina) invasion in Southwestern France. Toxicon, 55, 650-652. doi:10.1016/j.toxicon.2009.08.005

[11] Spradbery, J.P. (1973) Wasps: An account of the biology and natural history of social and solitary wasps. University of Washington Press, Seattle.

[12] Blot, J. (2009) Fiche technique apicole: Le frelon asi- 
atique (Vespa velutina)_Le piégeage des fondatrices. Bulletin Technique Apicole, 36, 55-58.

[13] Haxaire, J. and Villemant, C. (2010) Impact sur l'entomofaune des pièges à frelon asiatique. Insectes, 159, 1-6.

[14] Johnson, D.H. (2006) The many faces of replication. Crop Science, 46, 2486-2491. doi:10.2135/cropsci2006.04.0277

[15] Johnson, D.H. (2002) The importance of replication in wildlife research. Journal of Wildlife Management, 66, 919-932. doi:10.2307/3802926

[16] McCaffery, B.J. and Ruthrauff, D.R. (2004) Spatial variation in shorebird nest success: Implications for inference. Wader Study Group Bulletin, 103, 67-70.

[17] Tallmon, D.A. and Mills, L.S. (2004) Edge effects and isolation: Red-backed voles revisited. Conservation Biology, 18, 1658-1664. doi:10.1111/j.1523-1739.2004.00439.x

[18] Kelly, C.D. (2006) Replicating empirical research in behavioral ecology: How and why it should be done but rarely ever is. Quarterly Review of Biology, 81, 221-236. doi:10.1086/506236

[19] Monceau, K., Wattier, R., Dechaume-Moncharmont, F.-X., Motreuil, S. and Cézilly, F. (2011) Territoriality vs flocking in the Zenaida Dove, Zenaida aurita: Resource polymorphism revisited using morphological and genetic analyses. Auk, 128, 15-25. doi:10.1525/auk.2010.09247

[20] da Rocha, A.A. and Giannotti, E. (2007) Foraging activity of Protopolybia exigua (Hymenoptera, Vespidae) in different phases of the colony cycle, at an area in the region of the Médio São Francisco River, Bahia, Brazil. Sociobiology, 50, 813-831.

[21] Kasper, M.L., Reeson, A.F., Mackay, D.A. and Austin, A.D. (2008) Environmental factors influencing daily foraging activity of Vespula germanica (Hymenoptera, Vespidae) in Mediterranean Australia. Insectes Sociaux, 55, 288-295. doi:10.1007/s00040-008-1004-7

[22] de Castro, M.M., Guimaraes, D.L. and Prezoto, F. (2011)
Influence of environmental factors on the foraging activity of Mischocyttarus cassununga (Hymenoptera, Vespidae). Sociobiology, 58, 138-141.

[23] Taylor, L.R. (1963) Analysis of the effects of temperature on insects in flight. Journal of Animal Ecology, 32, 99117. doi: $10.2307 / 2520$

[24] Edwards, R. (1980) Social wasps: Their behaviour and control. Rentokil Ltd., Sussex.

[25] Sileshi, G. (2006) Selecting the right statistical model for analysis of insect count data by using information theoretic measures. Bulletin of Entomological Research, 96, 479-488.

[26] R Development Core Team. (2008) R: A language and environment for statistical computing. R Foundation for Statistical Computing, Vienna. http://www.R-project.org

[27] Perrard, A., Haxaire, J., Rortais, A. and Villemant, C. (2009) Observations on the colony activity of the Asian hornet Vespa velutina Lepeletier 1836 (Hymenoptera: Vespidae: Vespinae) in France. Annales de la Société Entomologique de France, 45, 119-127.

[28] Matsuura, M. (1984) Comparative biology of the five Japanese species of the genus Vespa (Hymenoptera, Vespidae). Bulletin of the Faculty of Agriculture Mie University, 69, 1-131.

[29] Matsuura, M. and Yamane, S. (1990) Biology of the Vespine Wasps. Springer Verlag, Berlin. doi:10.1007/978-3-642-75230-8

[30] Gourbière, S. and Menu, F. (2009) Adaptive dynamics of dormancy duration variability: Evolutionary trade-off and priority effect lead to suboptimal adaptation. Evolution, 63, 1879-1892. doi:10.1111/j.1558-5646.2009.00731.x

[31] Dauphin, P. and Thomas, H. (2009) Quelques données sur le contenu des pièges à frelons asiatiques posés à Bordeaux (Gironde) en 2009. Bulletin de la Société Linnéenne de Bordeaux, 37, 287-297. 